\title{
PRINCIPAIS CARBONILAS NO AR DE LOCAIS PÚBLICOS NO RIO DE JANEIRO
}

\section{Eduardo Delfino Sodré e Sérgio Machado Corrêa*}

Departamento de Química e Ambiental, Faculdade de Tecnologia, Universidade do Estado do Rio de Janeiro, Rodovia Presidente Dutra, km 298, 27537-000 Resende - RJ, Brasil

\section{Graciela Arbilla}

Departamento de Físico Química, Instituto de Química, Universidade Federal do Rio de Janeiro, Cidade Universitária, 21949-900 Rio de Janeiro - RJ, Brasil

\section{Márcia Marques}

Departamento de Engenharia Sanitária e Meio Ambiente, Faculdade de Engenharia, Universidade do Estado do Rio de Janeiro, 20550-900 Rio de Janeiro - RJ, Brasil

Recebido em 14/12/06; aceito em 10/8/07; publicado na web em 19/12/07

\begin{abstract}
MAIN CARBONYLS AT INDOOR PUBLIC PLACES OF RIO DE JANEIRO. An air quality evaluation of indoor environments with focus on lower carbonyls was carried out in 50 public places using TO-11A methodology. Formaldehyde levels (ranging from 12.5 to $1034 \mathrm{mg} \mathrm{m}^{-3}$ ) were above the threshold limit in 49 of 50 analyzed samples while acetaldehyde (ranging from 5.2 to 840 $\mathrm{mg} \mathrm{m}^{-3}$ ) and acetone (ranging from 5.5 to $4839 \mathrm{mg} \mathrm{m}^{-3}$ ) were respectively bellow the limits of OSHA and NIOSH in all samples. However all samples were bellow the threshold limits suggested by the Brazilian legislation - NR-15. A correlation study between the carbonyls and temperature and humidity was also done.
\end{abstract}

Keywords: formaldehyde; indoor; air pollution.

\section{INTRODUÇÃO}

A evolução da sociedade moderna e a mudança no estilo de vida vêm influenciando a qualidade do ar interior e, nas últimas décadas, a poluição "indoor" tem chamado a atenção da comunidade como um todo. O homem moderno vive, transita e trabalha a maior parte do tempo em espaços confinados, onde a baixa troca de ar gera o acúmulo de poluentes ${ }^{1}$, muitas vezes prejudiciais à saúde. Diferentemente do que ocorre com os poluentes exteriores, que geralmente sofrem processos de dispersão ao longo do dia, em ambientes confinados o indivíduo pode estar exposto a concentrações aproximadamente constantes de poluentes, por períodos relativamente longos. Há uma estimativa que grande parte das pessoas, particularmente em ambientes urbanos, passa entre 80 e $90 \%$ do seu tempo em ambientes confinados (dentro de casa, lazer, trabalho e meios de transporte). A natureza de tais ambientes é difícil de avaliar, pois muitos compostos químicos diferentes estão envolvidos e alguns deles não são perceptíveis como, por exemplo o radônio ${ }^{2}$. Outro fator complicador é o sinergismo entre os poluentes, principalmente na presença de fumantes.

A crise do petróleo na década de 70 alterou os rumos do condicionamento ambiental interno. A economia de energia passou a ser prioridade e isso reduziu gradativamente as taxas de renovação de ar, com o objetivo de redução de custos. Tais fatos estabeleceram uma situação de agressão à saúde nos ambientes interiores e um processo de degradação da qualidade do ar interior.

Espaços confinados, com pouca troca de ar, acumulam microorganismos, como fungos e bactérias, oriundos de infiltrações ou da má conservação do sistema de condicionamento de ar, substâncias químicas liberadas de materiais de uso, como móveis de escritório, produtos de combustão de fogões e aquecedores, material de limpeza e carpetes, que contribuem para a degradação da qua-

*e-mail: sergio@fat.uerj.br lidade do ar. É consenso que uma qualidade de ar interno deficiente pode afetar negativamente a saúde e, portanto, o desempenho e produtividade dos trabalhadores ${ }^{3}$.

A legislação específica para ambientes interiores tem dois enfoques: ocupacional e ambiental. Se o enfoque é a saúde ocupacional, as Normas Regulamentadoras do Ministério do Trabalho e Emprego, publicadas na Portaria 3.214 ${ }^{4}$ são aplicadas; quando o enfoque é ambiental, a Portaria $n^{\circ} 3.523$ do Ministério da Saúde ${ }^{5}$ é aplicada. Tal portaria determina que sejam objeto de regulamento técnico, a serem elaboradas por este Ministério, medidas específicas referentes a padrões de qualidade do ar em ambientes climatizados, no que diz respeito à definição de parâmetros físicos e composição química do ar de interiores, à identificação dos poluentes de natureza física, química e biológica, suas tolerâncias e métodos de controle, bem como pré-requisitos de projetos de instalações e de execução de sistemas de climatização.

A Agência Nacional de Vigilância Sanitária lançou uma Resolução ${ }^{6}$ que contém alguns parâmetros para qualidade do ar de ambientes climatizados. Apesar dessa Resolução reconhecer o formaldeído e demais Compostos Orgânicos Voláteis (COVs) como poluentes químicos, não estabelece nenhum padrão ou limite de exposição, limitando-se apenas a sugerir como principal medida de correção, a seleção criteriosa de materiais de construção, acabamento e mobiliário que contenham ou emitam menos formaldeído ou COVs, e o uso de produtos domissanitários que não contenham COVs. No Brasil, a exposição a certas substâncias acontece pela existência de padrões permissíveis ou pela completa ausência de padrões ${ }^{7}$. Esses padrões, embora sigam a "American Conference of Governmental Industrial Hygienists (ACGIH)", não são atualizados. Gioda e de Aquino Neto ${ }^{7}$ afirmaram que os compostos carcinogênicos não são regulamentados no Brasil e como a maioria dos compostos não foi submetida a todos os testes de toxicidade necessários é possível que, tanto no setor industrial quanto em ambientes interiores, estejamos expostos a uma carga mais elevada de poluentes. 
As carbonilas são uma família de compostos que possui uma extensa variedade de membros e, por esse motivo, têm um lugar de destaque na poluição atmosférica. Segundo de Andrade et al. ${ }^{8}$, os compostos carbonílicos - basicamente aldeídos e cetonas - são emitidos diretamente para atmosfera por um grande número de fontes. Desempenham um papel de grande relevância na química atmosférica por resultarem da primeira fotooxidação dos hidrocarbonetos, por se configurarem na maior fonte de radicais livres e como precursores de aerossol orgânico em áreas urbanas. Compostos carbonílicos são emitidos para a atmosfera a partir de uma grande variedade de fontes naturais e antropogênicas e podem ser formados in situ, a partir da fotólise e fotooxidação de hidro-carbonetos e outros compostos orgânicos. Ainda segundo de Andrade et al. ${ }^{8}$, as indústrias que mais emitem compostos carbonílicos são aquelas que sintetizam e usam esses compostos como matéria-prima, como refinarias e petroquímica, plantas de tratamento de esgotos, indústrias de plástico, tintas e vernizes. Concentrações atmosféricas de formaldeído e acetaldeído apresentam uma relação estreita com a composição da frota veicular.

Os compostos carbonílicos mais abundantes na atmosfera são o formaldeído (HCHO) e o acetaldeído $\left(\mathrm{CH}_{3} \mathrm{CHO}\right)$. Os aldeídos e cetonas afetam a química atmosférica de áreas poluídas por uma série de rotas bastante complexas. $\mathrm{O}$ aumento da concentração desses compostos diminui o período de indução de geração do "smog" fotoquímico. Dentre os membros desta classe com concentrações superiores na troposfera destacam-se formaldeído, acetaldeído, acetona, metil-etil-cetona (MEK), acroleína, crotonaldeído, metil-vinil-cetona (MVK), dimetil-éter, dietil-éter, ácido fórmico e acético. Dentre os citados, os de maior concentração na troposfera são o formaldeído, acetaldeído e a acetona. O monitoramento desses compostos é uma exigência das normas americanas?.

Numa das primeiras pesquisas realizadas no Brasil, Grosjean et $a l .{ }^{10}$ determinaram os níveis de carbonilas em três locais de Salvador - BA, e relacionaram os níveis de acetaldeído ao uso de etanol como combustível veicular. Resultados similares foram obtidos posteriormente ${ }^{11-13}$. De Andrade et $a l .{ }^{8}$ fizeram uma extensa revisão das principais carbonilas, suas fontes, reatividade, níveis de concentrações em vários locais do Brasil e do mundo e seus efeitos toxicológicos.

O objetivo do presente trabalho foi avaliar preliminarmente a qualidade de ar em 50 locais pertencentes a oito categorias de ambientes públicos na cidade do Rio de Janeiro e Niterói, em relação aos três principais compostos carbonílicos quanto aos indícios de carcinogenicidade dos mesmos: o formaldeído, o acetaldeído e a acetona, com vistas à verificação inicial da adequação de tais valores às normas nacionais e internacionais de qualidade de ar "indoor".

\section{PARTE EXPERIMENTAL}

A avaliação química da qualidade do ar do interior de locais públicos em relação às principais carbonilas (formaldeído, acetaldeído e acetona) foi realizada no período de novembro de 2005 a agosto de 2006. As localidades foram escolhidas com base nos seguintes critérios: quantidade de usuários do ambiente; ambiente onde as pessoas passam grande parte de seu tempo; acessibilidade para a amostragem. Quando possível, foi feito um inventário sobre o material de construção e revestimento, mobiliário, temperatura, umidade e intensidade luminosa desses locais. Os locais foram organizados em oito categorias: salas de cinema (6 locais); bibliotecas (6 locais); ônibus climatizado (6 locais); terminais rodoviários (5 locais); salas de aula (6 locais); recintos de hospital público (9 locais); salões de beleza (6 locais); cozinhas domiciliares (6 locais).

As amostras foram coletadas no período do dia de maior frequiência. A amostragem foi realizada pela técnica via seca, com re- ação química, empregando-se cartuchos de sílica revestidos de octadecil $\left(\mathrm{SiO}_{2}-\mathrm{C} 18\right)$ impregnados com uma solução ácida de 2,4dinitrofenil-idrazina (2,4-DNPH da Spectrum), com base na metodologia TO-11A da USEPA ${ }^{14}$. O preparo da solução de hidrazina foi feito adicionando-se $100 \mathrm{mg}$ de 2,4-DNPH, $85 \mathrm{~mL}$ de $\mathrm{CH}_{3} \mathrm{CN}$, $14 \mathrm{~mL}$ de $\mathrm{CCl}_{4}$ e $1 \mathrm{~mL}$ de $\mathrm{H}_{3} \mathrm{PO}_{4}$ para acidificar a solução. Essas substâncias foram colocadas em um recipiente escuro vedado e misturadas durante $3 \mathrm{~min}$. Foram retirados $50 \mathrm{~mL}$ da solução preparada e colocados em um funil de separação onde foram adicionados $200 \mathrm{~mL}$ de água bidestilada para extrair a hidrazina, onde a separação das fases é atingida após 10 min de repouso. A fase orgânica de $\mathrm{CCl}_{4}$ foi guardada para mais uma extração, sendo então descartada, sendo que poderia estar localizada a contaminação por hidrazonas (fase inferior). A solução menos densa (aquosa) foi então estocada no freezer em frasco âmbar vedado. O preparo da solução de DNPH seguiu o proposto por de Andrade ${ }^{15}$.

A vidraria necessária ao preparo dos cartuchos foi limpa com acetonitrila. Os cartuchos adquiridos (Waters Sep-Pak C18) foram limpos previamente pela passagem de $10 \mathrm{~mL}$ de metanol, que também tem a função de ativar e separar as partículas de $\mathrm{SiO}_{2}-\mathrm{C} 18$. A impregnação dos cartuchos foi realizada carregando a solução estoque em uma seringa de vidro e passando $7 \mathrm{~mL}$ desta pelo cartucho $\mathrm{SiO}_{2}-\mathrm{C} 18$, fazendo-se a solução impregnadora passar lentamente pelo cartucho $\left(<2,0 \mathrm{~mL} \mathrm{~min}^{-1}\right)$. Após a impregnação um fluxo de nitrogênio, a uma vazão de 300 a $400 \mathrm{~mL} \mathrm{~min}^{-1}$, foi passado pelos cartuchos para secagem do solvente. Foi empregado um cartucho previamente impregnado, como armadilha para eliminar qualquer impureza que estiver associada ao gás. Os cartuchos com tampas apropriadas foram envolvidos em papel alumínio e estocados em refrigerador a uma temperatura abaixo de $4{ }^{\circ} \mathrm{C}$, juntamente com papéis de filtro embebidos em solução DNPH, para armadilhar qualquer carbonila que possa contaminar os cartuchos. Antes de transportar os cartuchos para o trabalho de amostragem, foi verificada a integridade da 2,4-DNPH contida nos cartuchos, tendo em vista possíveis contaminações no preparo da solução durante o processo de impregnação ou mesmo durante a estocagem. Esta verificação é realizada eluindo-se um dos cartuchos impregnados com acetonitrila para um balão volumétrico de $5 \mathrm{~mL}$ e o eluato analisado por CLAE-UV, do mesmo modo como será descrito adiante na análise das amostras. Caso fosse identificada a contaminação da hidrazina, o lote de cartuchos preparado era inutilizado.

A quantificação e identificação foi realizada utilizando-se misturas padrão da Supelco (CARB Carbonyl-DNPH Mix 1) que contém 7 aldeídos: formaldeído, acetaldeído, acroleína, acetona, propionaldeído, butiraldeído e benzaldeído. Os padrões foram preparados em várias concentrações, sempre na faixa de 1,0 a $20 \mathrm{mg}$ $\mathrm{L}^{-1}$, usando-se como solvente acetonitrila, com o objetivo de obter um coeficiente de correlação superior a 0,99 para as curvas de calibração, usando a metodologia de padronização externa com o uso de 5 padrões.

As amostras foram coletadas em duplicata utilizando uma bomba amostradora autônoma (SKC modelo - PCXR4) a uma vazão média de $1,0 \mathrm{~L} \mathrm{~min}{ }^{-1}$ por aproximadamente $2 \mathrm{~h}$. Tais parâmetros são regulados pela quantidade de carbonilas que o cartucho suporta. Como cada cartucho tem cerca de $2 \mathrm{mg}$ de DNPH, é recomendável amostrar até $75 \%$ de sua capacidade de retenção de carbonilas. Caso esta capacidade ultrapassada pode-se não reter todas as carbonilas no cartucho. Isto é verificado procedendo-se à amostragem com dois cartuchos em série, de modo a ajustar o conjunto vazão e duração e não se observar a presença de carbonilas no segundo cartucho. Diversas amostras tiveram que ser descartadas em função da saturação do cartucho. Ao final da amostragem o cartucho era retirado, lacrado e identificado. As amostras eram estocadas em local 
refrigerado e protegidas da luz até a análise, por no máximo 5 dias, segundo Castro et al. ${ }^{16}$. Foi reservado sempre um número de $\mathrm{N}^{1 / 2}$ de cartuchos para ensaios em branco, onde $\mathrm{N}$ é o número de cartuchos amostrados, para um número mínimo de 2 cartuchos. Os cartuchos em branco foram transportados para o local de amostragem e com eles foram realizadas as mesmas operações que com os demais, a não ser a passagem do ar pela bomba.

Os cartuchos foram então eluídos pela passagem de acetonitrila até um volume de $5 \mathrm{~mL}$. A análise foi realizada usando cromatografia líquida de alto desempenho (CLAE), com detecção UV a $360 \mathrm{~nm}^{14}$. Empregou-se um volume de injeção de $20 \mu \mathrm{L}$, fase móvel $45 \%$ de acetonitrila e $55 \%$ de água (v/v) a uma vazão de 1,3 a $2,0 \mathrm{~mL}$ min ${ }^{1}$ e uma coluna $\mathrm{C}_{18} 150 \mathrm{~mm}$ x 3,9 $\mathrm{mm}$ x 5,0 $\mu \mathrm{m}$. Em todos os locais amostrados os dois cartuchos empregados apresentaram um desvio inferior a $15 \%$ entre eles.

Os resultados encontrados em cada categoria foram comparados com os valores de referência do "National Institute for Occupational Safety and Health (NIOSH)" e do "Occupational Safety and Health Administration (OSHA)". Os dados também foram correlacionados entre si usando-se como ferramentas o diagrama de dispersão e o coeficiente de correlação de Pearson.

\section{RESULTADOS E DISCUSSÃO}

A Tabela 1 contém os resultados obtidos para as 50 amostras. Os coeficientes de correlação de Pearson entre pares de carbonilas e entre cada carbonila e as variáveis temperatura e umidade em cada uma das oito categorias de ambientes públicos são apresentados, respectivamente, nas Tabelas 2 e 3 .

\section{Salas de cinema}

A correlação entre as concentrações de carbonilas encontradas nas salas de cinema, assim como a correlação da concentração de carbonila com as variáveis temperatura e umidade foi, em geral, baixa. Diversas são as fontes possíveis de tais emissões, como cortinas, cadeiras de material sintético, carpetes e revestimento de fórmica e carpete, além da baixa troca de ar com o meio externo. As salas de cinema 2, 3, 4 e 5 encontravam-se em um mesmo shopping center e apresentaram valores mais próximos se comparados às salas 1 e 6 , provavelmente devido ao fato das primeiras serem estruturalmente semelhantes e sofrerem a influência do ar ambiente interno do shopping.

\section{Ônibus climatizados}

Os coeficientes de correlação entre os teores encontrados de carbonilas nos ônibus climatizados foram relativamente altos $(>0,73)$, o que sugere que as fontes de tais emissões eram internas. A correlação entre cada carbonila e as variáveis temperatura e umidade foi baixa. Emissões mais altas de carbonilas foram observadas nos ônibus aparentemente mais novos $(4,5$ e 6$)$, que faziam as linhas para a zona sul do Rio de Janeiro. Tal resultado está de acordo com o argumento de que os materiais mais novos emitem mais carbonilas e que o fluxo de emissão diminui com o tempo. No entanto, uma avaliação temporal e um inventário mais detalhado de todos os ônibus são necessários para confirmar essa hipótese. Somente a cidade do Rio possui cerca de 850 linhas e aproximadamente 7200 ônibus circulando, com um número de usuários transportados de cerca de 65 milhões ${ }^{17}$. A cidade do Rio de Janeiro, proporcionalmente a seu tamanho de metrópole, provavelmente possui um dos piores sistemas de transporte por ônibus do mundo, por ausência de integração, sobreposição de linhas, concorrência direta e indireta com os transportes de massa, ausência de regula-
Tabela 1. Resultados das 50 amostras em 8 categorias de locais (dados em $\mu \mathrm{g} \mathrm{m}^{-3}$ )

\begin{tabular}{|c|c|c|c|c|}
\hline Localidades & Amostra & Formaldeído & Acetaldeído & Acetona \\
\hline Salas de & 1 & 174 & 223 & 19,3 \\
\hline \multirow[t]{5}{*}{ Cinema } & 2 & 95,9 & 111 & 45,2 \\
\hline & 3 & 36,0 & 58,1 & 16,0 \\
\hline & 4 & 70,6 & 89,6 & 35,5 \\
\hline & 5 & 125 & 98,5 & 29,0 \\
\hline & 6 & 194 & 24,5 & 143 \\
\hline Ônibus & 1 & 49,1 & 47,2 & 35,2 \\
\hline \multirow[t]{5}{*}{ Climatizado } & 2 & 27,7 & 30,3 & 29,1 \\
\hline & 3 & 12,5 & 5,2 & 5,5 \\
\hline & 4 & 53,4 & 54,9 & 28,6 \\
\hline & 5 & 46,0 & 98,1 & 73,0 \\
\hline & 6 & 95,9 & 88,8 & 68,5 \\
\hline \multirow[t]{6}{*}{ Salas de Aula } & 1 & 701 & 394 & 12,2 \\
\hline & 2 & 162 & 446 & 12,3 \\
\hline & 3 & 169 & 310 & 90,0 \\
\hline & 4 & 106 & 327 & 101 \\
\hline & 5 & 158 & 480 & 151 \\
\hline & 6 & 58,7 & 28,9 & 23,2 \\
\hline Salões de & 1 & 187 & 65,9 & 1939 \\
\hline \multirow[t]{5}{*}{ Beleza } & 2 & 203 & 59,3 & 1867 \\
\hline & 3 & 1034 & 840 & 2389 \\
\hline & 4 & 171 & 80,5 & 4042 \\
\hline & 5 & 622 & 375 & 2654 \\
\hline & 6 & 232 & 327 & 4839 \\
\hline Terminais & 1 & 75,0 & 107 & 115 \\
\hline \multirow[t]{4}{*}{ Rodoviários } & 2 & 183 & 119 & 371 \\
\hline & 3 & 203 & 210 & 236 \\
\hline & 4 & 136 & 152 & 32,4 \\
\hline & 5 & 128 & 177 & 18,1 \\
\hline \multirow[t]{6}{*}{ Bibliotecas } & 1 & 58,6 & 30,2 & 19,8 \\
\hline & 2 & 178 & 76,0 & 45,8 \\
\hline & 3 & 181 & 72,0 & 63,0 \\
\hline & 4 & 81,6 & 21,5 & 29,2 \\
\hline & 5 & 70,0 & 29,0 & 17,4 \\
\hline & 6 & 83,4 & 25,6 & 24,9 \\
\hline Hospital & 1 & 297 & 263 & 112 \\
\hline \multirow[t]{8}{*}{ Público } & 2 & 171 & 241 & 57,8 \\
\hline & 3 & 94,5 & 76,3 & 114 \\
\hline & 4 & 151 & 194 & 82,8 \\
\hline & 5 & 77,6 & 69,7 & 37,9 \\
\hline & 6 & 212 & 207 & 164 \\
\hline & 7 & 444 & 268 & 160 \\
\hline & 8 & 313 & 722 & 74,9 \\
\hline & 9 & 292 & 142 & 13,8 \\
\hline Cozinhas & 1 & 97,4 & 78,0 & 78,4 \\
\hline \multirow[t]{5}{*}{ Domiciliares } & 2 & 69,2 & 55,1 & 58,1 \\
\hline & 3 & 26,6 & 27,1 & 17,3 \\
\hline & 4 & 47,2 & 29,3 & 10,5 \\
\hline & 5 & 35,4 & 33,2 & 14,2 \\
\hline & 6 & 28,6 & 12,6 & 7,3 \\
\hline
\end{tabular}

mentação e fiscalização adequada. Para agravar o quadro, nos últimos 10 anos houve perda de usuários para os demais meios de transporte, especialmente para o transporte alternativo. 
Tabela 2. Coeficientes de correlação de Pearson (CCP) entre pares de carbonilas em diferentes categorias de ambientes amostrados

\begin{tabular}{lccccccc}
\hline CCP & $\begin{array}{c}\text { Salas de } \\
\text { cinema }\end{array}$ & $\begin{array}{c}\text { Ônibus } \\
\text { climatizados }\end{array}$ & $\begin{array}{c}\text { Salas de } \\
\text { aula }\end{array}$ & $\begin{array}{c}\text { Salões de } \\
\text { beleza }\end{array}$ & $\begin{array}{c}\text { Terminais } \\
\text { rodoviários }\end{array}$ & $\begin{array}{c}\text { Biblioteca } \\
\text { Hospital } \\
\text { público }\end{array}$ & $\begin{array}{c}\text { Cozinhas } \\
\text { domiciliares }\end{array}$ \\
\hline $\begin{array}{l}\text { Acetaldeído/ } \\
\text { Acetona }\end{array}$ & $-0,57$ & $\mathbf{0 , 7 6}$ & 0,32 & $-0,008$ & $-0,15$ & $\mathbf{0 , 8 6}$ & 0,06 \\
$\begin{array}{l}\text { Formaldeído/ } \\
\begin{array}{l}\text { Acetona } \\
\text { Formaldeído/ } \\
\text { Acetaldeído }\end{array}\end{array}$ & 0,60 & $\mathbf{0 , 7 3}$ & $-0,38$ & $-0,26$ & 0,63 & $\mathbf{0 , 9 4}$ & 0,32 \\
\hline
\end{tabular}

Tabela 3. Coeficientes de correlação de Pearson entre cada carbonila e as variáveis temperatura e umidade nos ambientes amostrados

\begin{tabular}{lccccccccc}
\hline & CCP & $\begin{array}{c}\text { Salas de } \\
\text { cinema }\end{array}$ & $\begin{array}{c}\text { Onibus } \\
\text { climatizados }\end{array}$ & $\begin{array}{c}\text { Salas de } \\
\text { aula }\end{array}$ & $\begin{array}{c}\text { Salões de } \\
\text { beleza }\end{array}$ & $\begin{array}{c}\text { Terminais } \\
\text { rodoviários }\end{array}$ & $\begin{array}{c}\text { Biblioteca } \\
\text { Hospital } \\
\text { público }\end{array}$ & $\begin{array}{c}\text { Cozinhas } \\
\text { domiciliares }\end{array}$ \\
\hline Temperatura & Formaldeído & $-0,27$ & 0,12 & $\mathbf{0 , 7 5}$ & 0,37 & $-0,07$ & 0,21 & 0,12 & $-0,64$ \\
& Acetaldeído & 0,52 & $-0,13$ & 0,21 & 0,51 & 0,22 & 0,40 & $-0,12$ & $-0,59$ \\
\multirow{4}{*}{ Umidade } & Acetona & 0,45 & 0,09 & 0,39 & $\mathbf{0 , 7 4}$ & $-0,58$ & 0,09 & 0,08 & $-0,62$ \\
& Formaldeído & $-0,23$ & $-0,43$ & 0,12 & 0,57 & $\mathbf{0 , 7 9}$ & 0,41 & $-0,43$ & $-0,0,27$ \\
& Acetaldeído & $-0,45$ & $-0,56$ & 0,66 & 0,49 & $-0,005$ & 0,54 & $-0,56$ & $-0,29$ \\
& Acetona & 0,38 & $-0,68$ & 0,29 & $\mathbf{- 0 , 7 6}$ & $\mathbf{0 , 8 5}$ & 0,49 & $-0,68$ & $-0,42$ \\
\hline
\end{tabular}

\section{Salas de aula}

Os coeficientes de correlação entre emissões de carbonilas foram baixos, apesar da correlação razoável entre as variáveis formaldeído/temperatura e acetaldeído/ umidade. A baixa correlação como um todo sugere que as fontes de emissão são provavelmente externas. Tal resultado está de acordo com o fato de não haver sistema de climatização artificial nas salas estudadas, o que contribui para o aumento da concentração das carbonilas no meio interno, e o fato de que todas as salas de aula possuíam janelas e eram bem ventiladas. Um fator relevante é que as salas 1 a 5 pertenciam ao complexo escolar do Sambódromo e apresentaram níveis de acetaldeído muito semelhantes e relativamente altos. A proximidade do complexo escolar do Sambódromo com uma fábrica de cerveja e com a Avenida Presidente Vargas pode estar relacionada com os níveis de acetaldeído encontrados. Observa-se que as salas 2 a 5, que pertencem ao mesmo complexo escolar, possuem um perfil muito semelhante para o nível de formaldeído, e diferente da sala 1 que apresentou seis vezes mais formaldeído. A concentração alta de formaldeído na sala 1 pode ser devida a alguma fonte emissora interna ou, um pico no nível de concentração de fontes externas no dia da amostragem. Observa-se que apesar das amostragens terem sido em torno de $2 \mathrm{~h}$ somente e algumas salas terem sido amostradas em dias diferentes, os níveis de formaldeído sugerem um perfil para salas de aula. Tratando-se de crianças do préescolar e não adultos, os resultados indicam que essas crianças podem estar sendo expostas a concentrações perigosas de formaldeído. Para confirmação de tal hipótese, um maior número de amostragens é necessário, inclusive da área externa para comparação. A sala 6 pertencente a uma escola no morro de Santa Teresa, a qual apresentou valores bem mais baixos que as demais.

\section{Salões de beleza}

Houve uma correlação positiva para as variáveis formaldeído/ acetaldeído e acetona/temperatura. Tendo em conta que todos os salões de beleza possuíam sistema de climatização artificial e utiliza- vam vários produtos com formol e acetona em sua composição, sugere-se que as fontes das emissões eram internas. Interessante notar que os níveis de acetona estavam extremamente altos em relação a outras categorias de localidade amostradas e que esses níveis eram concordantes entre todos os salões amostrados, mesmo sendo em locais e dias diferentes. Isto se deve provavelmente ao uso intenso da acetona como removedor de esmaltes e à volatilidade da mesma. Segundo a Folha de São Paulo de 15/05/2005, 332 mulheres do Rio de Janeiro procuraram a Vigilância Sanitária da cidade para reclamar de reações causadas pela técnica de escova progressiva. As queixas referiam-se à queda de cabelo, ardência nos olhos, queimaduras no couro cabeludo e problemas respiratórios. Dois salões foram interditados e 36 foram multados. Segundo a ANVISA, o uso do formaldeído em alisantes de cabelo nunca foi autorizado. Entretanto, existe a Lei Federal $n^{\circ} 437 / 77^{18}$ que autoriza o uso de formaldeído em alguns cosméticos como esmaltes e xampus, apenas como conservante, em concentrações baixas.

\section{Terminais rodoviários}

Nos terminais rodoviários as correlações foram razoáveis entre formaldeído/acetaldeído e formaldeído/acetona. Houve uma melhor correlação entre formaldeído/umidade e acetona/umidade. Sugere-se que apesar dos terminais serem semi-abertos, as fontes provavelmente eram internas. Nestes locais, a concentração de veículos pesados é alta e os motores funcionam em modo estacionário e em baixa rotação, situação na qual os motores apresentam baixa eficiência e, conseqüentemente, maiores níveis de emissão de poluentes. É sabido que em áreas urbanas, grande parte da poluição "indoor" é oriunda de fontes externas. Segundo Corrêa ${ }^{19}$, nos últimos anos os níveis desses poluentes aumentaram significativamente devido ao aumento da frota veicular movida a GNV e álcool.

\section{Bibliotecas}

Houve correlação alta entre as carbonilas e correlação baixa entre as carbonilas e as variáveis temperatura e umidade. Righi et 
$a l{ }^{20}$ estudando quatro bibliotecas na Universidade de Modena, Itália encontraram níveis de formaldeído de 13,6; 30,7 e 5,0 $\mu \mathrm{g} \mathrm{m}^{-3}$, ou seja, muito abaixo dos valores encontrados no presente trabalho.

\section{Hospitais}

Nos ambientes hospitalares, todos os locais amostrados possuiam sistema de climatização artificial e os níves das carbonilas foram altos. Portanto, apesar da baixa correlação entre as carbonilas e as variáveis temperatura e umidade, os resultados obtidos sugerem que as fontes são internas. $\mathrm{O}$ ambiente hospitalar utiliza rotineiramente vários produtos médicos ou de limpeza que contêm COVs.

\section{Cozinhas domiciliares}

A correlação entre as carbonilas foi alta e não houve correlação com temperatura e umidade. Como a amostragem foi realizada durante o período que a cozinha estava sendo utilizada, sugere-se que as fontes são internas.

Para o formaldeído observa-se que todos os 50 locais amostrados, com exceção de um local (ônibus climatizado 3, concentração de formaldeído $=12,5 \mu \mathrm{g} \mathrm{m}^{-3}$ ), estavam acima do valor de exposição de $20 \mu \mathrm{g} \mathrm{m}^{-3}$ recomendado pela NIOSH. O formaldeído também ultrapassou o limite de exposição da OSHA $\left(930 \mu \mathrm{g} \mathrm{m}^{-3}\right)$ em pelo menos um local: o salão de beleza $3\left(1034 \mu \mathrm{g} \mathrm{m}^{-3}\right)$, mas não ultrapassou o limite em nenhum local quanto à NR $15\left(2300 \mu \mathrm{g} \mathrm{m}^{-3}\right)$. Em relação ao acetaldeído todas as amostras estavam dentro do limite de exposição sugerido pela NR $15\left(180.000 \mu \mathrm{g} \mathrm{m}^{-3}\right)$ e pela OSHA $(360.000 \mu \mathrm{g}$ $\mathrm{m}^{-3}$ ). Com relação à acetona, todos os locais estavam dentro do limite de exposição recomendado pela NIOSH $\left(5.900 .000 \mu \mathrm{g} \mathrm{m}^{-3}\right)$, OSHA $\left(2.400 .000 \mu \mathrm{g} \mathrm{m}^{-3}\right)$ e NR15 $\left(1.870 .000 \mu \mathrm{g} \mathrm{m}^{-3}\right)$.

Segundo Gioda e de Aquino Neto ${ }^{7}$, com base numa revisão bibliográfica, diversos locais públicos confinados no Rio de Janeiro e São Paulo apresentaram valores de formaldeído variando de 2,2 a $86 \mathrm{~g} \mathrm{~m} \mathrm{~m}^{-3}$ e um setor industrial (Biomanguinhos-Fiocruz) em particular apresentou o valor de $608 \mu \mathrm{g} \mathrm{m}^{-3}$. Segundo estes autores, o acetaldeído apresentou teores variando entre 0,6 a $44 \mu \mathrm{g} \mathrm{m}^{-3}$. Para ambas as carbonilas os valores descritos eram inferiores aos encontrados no presente trabalho. A elevação nos teores de formaldeído e acetaldeído foi recentemente atribuída ao incremento no uso de GNV pela frota do Rio de Janeiro, segundo Corrêa e Arbilla ${ }^{12}$. Quando os valores dos 50 locais amostrados são agregados, encontra-se um coeficiente de correlação $r=0,75$ entre formaldeído e acetaldeído, indicando que as fontes destes dois compostos podem ter origens semelhantes, ao contrário das baixas correlações do formaldeído com a acetona $(r=0,39)$ e do acetaldeído com a acetona $(r=0,26)$, indicando que a acetona provavelmente possui uma fonte diferente das carbonilas menores.

\section{CONCLUSÃO}

O monitoramento contínuo de poluentes do ar em ambientes públicos interiores deve ser incorporado à cultura da sociedade moderna. Os países desenvolvidos esforçam-se para reduzir os níveis de exposição das populações a poluentes perigosos, e isso certamente se reflete nos custos de tratamento de saúde e na qualidade de vida.

No Brasil, esforços têm sido feitos no intuito de melhorar a qualidade do ar de ambientes confinados, tais como a criação da Portaria $n^{\circ} 3.523$ de 28/08/1998 do Ministério da Saúde ${ }^{5}$ que regulamenta as normas para avaliação e controle de ambientes climatizados de uso coletivo e a Resolução n ${ }^{\circ} 9$ de 16/01/2003 da ANVISA $^{6}$. No entanto, tais normas não são suficientes. Para o formaldeído - substância cancerígena segundo a IARC (2004) - é urgente uma mudança nos níveis de exposição para ambientes confinados, climatizados ou não, face aos estudos recentes e à tendência mundial para o controle desse poluente. Uma breve comparação entre os limites da NIOSH e da OSHA ilustra a grande disparidade entre as normas de um mesmo país: a NIOSH é uma agência ligada ao Departamento de Saúde e a OSHA, ao Departamento de Trabalho, ambos dos EUA. Tais agências possuem entendimentos diferenciados quanto aos limites aceitáveis de exposição. Para a realidade brasileira, estudos mais aprofundados são necessários, principalmente para se avaliar os valores médios destes poluentes no ar externo e aspectos tais como sazonalidade, antes do estabelecimento de limites nacionais. Limites tais como $20 \mu \mathrm{g} \mathrm{m}^{-3}$ estabelecido pela NIOSH para o formaldeído serão provavelmente impossíveis de serem atendidos em algumas metrópoles, tais como a cidade do Rio de Janeiro que apresenta valores bem superiores a este ao longo do ano, basicamente em decorrência das emissões automotivas de gasolina, GNV e diesel.

\section{REFERÊNCIAS}

1. Parker, J.; The CIBSE Journal 1991, 15, 24.

2. Raw, G.; The CIBSE Journal 1997, 19, 27.

3. World Health Organization (WHO); World Health Report 2002: Reducing Risks, Pro-healthy Life, Chapter 4, Geneva.

4. Ministério do Trabalho e Emprego; Portaria 3.214, Brasil, 1978.

5. Ministério da Saúde; Portaria 3.523, Brasil, 1998.

6. ANVISA; Resolução $n^{\circ} 9$, de 16 de janeiro de 2003.

7. Gioda, A.; de Aquino Neto, F. R.; Quim. Nova 2003, 26, 359.

8. de Andrade, M. V. A. S.; Pinheiro, H. L. C.; Pereira, P. A. de P.; de Andrade, J. B.; Quim. Nova 2002, 25, 1117.

9. U. S. EPA: Code of Federal Regulations. Title 40, Part 58. Ambient Air Quality World Surveillance, Final Rule Federal Register, Vol. 58, No. 28, February 12, 1993.

10. Grosjean, D.; Miguel, A. H.; Tavares, T.; Atmos. Environ. 1990, $24 B, 101$.

11. de Andrade, J. B.; Andrade, M. V.; Pinheiro, H. L. C.; J. Braz. Chem. Soc. 1998, 9, 219

12. Corrêa, S. M.; Arbilla, G.; Atmos. Environ. 2005, 39, 4513.

13. Corrêa, S. M.; Martins, E.; Arbilla, G.; Atmos. Environ. 2003, 37, 23.

14. U. S. EPA; Compendium Method TO-11A. EPA-625/R-96/010b. Cincinnati, 1997.

15. de Andrade, M. V. A. S.; Tese de Doutorado, Universidade Federal da Bahia, Brasil, 2001.

16. Castro, B. C. S.; Corrêa, S. M.; Arbilla, G.; Resumos do IX Encontro Regional da SBQ-RIO, Rio de Janeiro, Brasil, 2003.

17. http://www.armazemdedados.rio.rj.gov.br, acessada em Novembro 2006

18. Lei Federal n. ${ }^{\circ} 437$, de 20 de agosto de 1977.

19. Corrêa, S. M.; Tese de Doutorado, Universidade Federal do Rio de Janeiro, Brasil, 2003.

20. Righi, E.; Aggazzotti, G.; Fantuzi, G.; Ciccarese, V.; Predieri, G.; Sci. Total Environ. 2002, 286, 41. 